Rabaska

Revue d'ethnologie de l'Amérique française

Gagnon, Serge. Familles et presbytères. Québec, Presses de l’Université Laval, 2013, 174 p. ISBN 978-2-7637-9968-1

\title{
Laurence Provencher-St-Pierre
}

Volume 15, 2017

URI : https://id.erudit.org/iderudit/1041146ar

DOI : https://doi.org/10.7202/1041146ar

Aller au sommaire du numéro

Éditeur(s)

Société québécoise d'ethnologie

ISSN

1703-7433 (imprimé)

1916-7350 (numérique)

Découvrir la revue

Citer ce compte rendu

Provencher-St-Pierre, L. (2017). Compte rendu de [GAGNON, SERGE. Familles et presbytères. Québec, Presses de l’Université Laval, 2013, 174 p.

ISBN 978-2-7637-9968-1]. Rabaska, 15, 250-252.

https://doi.org/10.7202/1041146ar

Ce document est protégé par la loi sur le droit d'auteur. L'utilisation des services d'Érudit (y compris la reproduction) est assujettie à sa politique d'utilisation que vous pouvez consulter en ligne.

https://apropos.erudit.org/fr/usagers/politique-dutilisation/
Cet article est diffusé et préservé par Érudit.

Érudit est un consortium interuniversitaire sans but lucratif composé de l'Université de Montréal, l'Université Laval et l'Université du Québec à Montréal. Il a pour mission la promotion et la valorisation de la recherche. https://www.erudit.org/fr/ 
dienne et accomplit la difficile tâche de reconstituer leur parcours pendant plusieurs générations, de l'Acadie au Nord-Ouest, du Cadien au Métis. Il utilise avec beaucoup de prudence les récits de voyage et les journaux de poste, pour en extraire de précieux renseignements sur les hommes étudiés. Il faut toutefois être plus critique pour ce qui est du contexte commercial de la traite des fourrures.

Gratien Allaire

Professeur émérite, Université Laurentienne

Gagnon, Serge. Familles et presbytères. Québec, Presses de 1'Université Laval, 2013, 174 p. ISBN 978-2-7637-9968-1.

L'historien Serge Gagnon conclut avec Familles et presbytères (2013) sa trilogie sur l'histoire des curés au Bas-Canada. Dans cet essai qu'il qualifie de « biographie collective », Gagnon étudie la période allant de 1790 à 1830 et s'appuie principalement sur la correspondance des curés avec leur évêque. Comme dans Quand le Québec manquait de prêtre (2006) et L'Argent du curé de campagne (2010), l'auteur propose une analyse thématique de cette correspondance. Dans ce dernier ouvrage, Gagnon tâche de déconstruire l'imagerie populaire du curé de campagne habitant un presbytère monumental, une image qui s'appuie davantage sur la réalité des prêtres de la fin du $\mathrm{XIX}^{\mathrm{e}}$ siècle et du début du $\mathrm{XX}^{\mathrm{e}}$ siècle. Il resitue plutôt le service pastoral dans le contexte propre à cette période du développement des paroisses et présente le presbytère comme un espace où s'articulent différents rapports de force. L'ouvrage se structure en trois chapitres. Il aborde d'abord les enjeux reliés à la construction, à l'entretien et à l'usage du presbytère ; le profil socioéconomique des curés de paroisses et ses conséquences ; puis, les liens que les curés entretenaient avec les membres de leurs familles pendant leur service pastoral.

Dans les paroisses du Bas-Canada, l'obligation de fournir une demeure convenable au curé entraîne parfois des situations conflictuelles entre le clergé paroissial, les paroissiens et l'évêché. En première partie, Serge Gagnon présente les enjeux matériels concernant la maison presbytérale. Qui est responsable de sa construction? Qui choisit son emplacement ? Qui doit financer et exécuter les travaux de rénovation? Quels matériaux doivent être utilisés ? Quels sont les droits du curé et les devoirs des paroissiens ? Comment étaient sanctionnés les paroissiens qui tardaient à participer aux travaux ? Dans le contexte de cette époque qui se caractérise par la création de nombreuses nouvelles paroisses, d'un nombre insuffisant de curés pour 
répondre à la demande et d'une population souvent pauvre, la construction ou la rénovation d'un presbytère devient une source de conflits. La correspondance des curés avec l'évêché documente ces enjeux. Par exemple, elle révèle les mauvaises conditions matérielles dans lesquelles certains curés vivent et les stratégies mises en place pour contraindre les paroissiens à rénover ou à bâtir un nouveau presbytère. Ainsi, devant des paroissiens peu empressés, l'évêque peut menacer de retirer le prêtre en place. Inversement, les paroissiens peuvent décider de ne pas rénover le bâtiment pour se débarrasser d'un curé non apprécié. Il peut également arriver que le curé n'habite pas le presbytère qui lui est destiné et le laisse à l'abandon, ce qui oblige les paroissiens à gérer un bâtiment inoccupé. Plusieurs situations expliquent cet abandon. En effet, dans ce contexte de pénurie, les curés peuvent desservir plus d'une paroisse et donc délaisser le presbytère de l'une d'elles. Aussi, le curé peut être invité par son évêque à quitter les lieux s'ils sont insalubres ou inadéquats. Encore, le désir de confort et d'autonomie ou le refus de subir les conséquences des réparations mal exécutées amènent certains prêtres à quitter le presbytère et à faire l'achat d'une propriété. Ensuite, Gagnon précise que la maison presbytérale n'était pas réservée à l'usage unique du curé. De dimension plutôt modeste, le bâtiment comprenait un logement pour le curé ainsi qu'une salle publique pour les paroissiens. Ce partage de l'espace était aussi une source de conflits.

En s'intéressant à la manière dont les prêtres ont financé leur accès à la prêtrise - l'évêché exigeant du futur prêtre qu'il se procure une rente Gagnon dresse un portrait des origines familiales des prêtres. Ceux-ci sont majoritairement originaires des villes et sont issus de la classe moyenne ou de la petite bourgeoisie. Dans ce dernier cas, le père occupe généralement une profession faiblement scolarisée, car rares sont les curés provenant de la bourgeoisie des professions libérales. Malgré leurs origines urbaines, les prêtres demeurent sensibles aux difficultés de la paysannerie, notamment en ce qui a trait à la pénurie des terres cultivables et au surpeuplement qui caractérisent cette période. Poursuivant l'analyse, Gagnon tente de démontrer le rapport entre l'origine du prêtre, la profession de son père et le style de vie adopté une fois curé. Il soutient que : « [1]'enfant du peuple se hisse aux échelons supérieurs de la petite bourgeoisie rurale, tandis que le fils de petit-bourgeois reproduit au presbytère un niveau et un style de vie déjà vécus dans la famille [...]. » (p. 108.)

Ensuite, l'auteur aborde la question du rapport entretenu par le curé avec les membres de sa famille et ses répercussions sur son service pastoral. Ces relations peuvent avoir des conséquences positives sur la vie au presbytère et sur le statut social de la famille. Par exemple, lorsque le curé accueille 
une sœur, une nièce ou une cousine qui agit comme servante, cela augmente les chances de la jeune fille de se trouver un mari occupant une position sociale avantageuse et ainsi influer sur la prospérité de la famille. Le prêtre peut également prendre à sa charge ses parents vieillissants ou ses jeunes frères et sœurs. Si ce rôle de soutien familial est généralement approuvé par l'évêché et par les paroissiens, il arrive que les opinions soient plus mitigées et que les attentes de la famille deviennent plus lourdes pour le prêtre concerné. C'est le cas, par exemple, lorsque le père souhaite que le prêtre lui rembourse ses dettes d'études ou lorsque la famille exige qu'il envoie de l'argent pour subvenir à leurs besoins. Bien que la présence de la mère au presbytère soit généralement considérée comme un gage des bonnes mœurs du curé, la perception peut changer lorsque la mère vieillissante ne pouvant plus participer à l'entretien du presbytère devient une charge pour le prêtre. Il arrive également, dans certains cas, que les membres de la famille soient considérés comme une présence indésirable au presbytère ou une mauvaise influence pour le prêtre délinquant exigeant parfois l'intervention de l'évêque.

Si à quelques reprises le lecteur peut se sentir submergé par les nombreux exemples et anecdotes relatés dans cet ouvrage, ces éléments sont contrebalancés par le fait que l'auteur a produit en conclusion un résumé habile et efficace. Le corpus de données étudié est riche, mais impose certaines limites qui ont façonné l'analyse. Gagnon précise : «Il est vrai que mes sources sont plus bavardes sur les situations qui font problème que sur celles qui se déroulent sans histoire. Il faut pourtant se contenter d'anecdotes à défaut de sources plus fiables comme des recensements périodiques » (p. 153). Ainsi, la nature des données contraint l'auteur à émettre plusieurs hypothèses qui semblent accorder une influence surdimensionnée aux origines sociales pour expliquer un comportement, une attitude, un caractère ou l'adoption d'un certain mode de vie. Cependant, ces éléments n'enlèvent rien à la qualité du portrait des prêtres de la fin du XVIII ${ }^{\mathrm{e}}$ et du premier tiers du XIX ${ }^{\mathrm{e}}$ siècle dressé par l'auteur. Serge Gagnon peint de manière originale le presbytère comme espace social et lieu de tractation. Il rend visibles les jeux de pouvoir et les stratégies de négociation employées par les diverses parties que représentent la population locale, le curé, sa famille et l'évêché. En ce sens, cette biographie collective atteint son objectif : l'image du curé au Bas-Canada se précise et se singularise face à la réalité des prêtres des périodes suivantes.

Laurence Provencher-St-Pierre

Université du Québec à Montréal 